\title{
Evaluation of the Effects of Elevated Intra-abdominal Pressure on the Respiratory Mechanics in Mechanically Ventilated Patients
}

\author{
Aleksandra Gavrilovska-Brzanov ${ }^{1 *}$, Zorka Nikolova ${ }^{1}$, Nikola Jankulovski ${ }^{2}$, Mirjana Sosolceva ${ }^{1}$, Gordana Taleska ${ }^{1}$, Maja \\ Mojsova-Mijovska ${ }^{1}$, Marija Jovanovski-Srceva ${ }^{1}$, Darko Angusev ${ }^{1}$, Darko Sazdov ${ }^{3}$, Nikola Brzanov ${ }^{4}$ \\ ${ }^{1}$ University Clinic of Anesthesiology, Reanimation and Intensive Care, KARIL, Faculty of Medicine, Ss Cyril and Methodius \\ University of Skopje, Republic of Macedonia; ${ }^{2}$ University Clinic for Digestive Surgery, Faculty of Medicine, Ss Cyril and \\ Methodius University of Skopje, Republic of Macedonia; ${ }^{3}$ ACIBADEM-Sistina, Anesthesiology, Skopje, Republic of \\ Macedonia; ${ }^{4}$ University Clinic of Surgery, ER Department, Faculty of Medicine, Ss Cyril and Methodius University of Skopje, \\ Republic of Macedonia
} Citation: Gavrilovska-Brzanov A, Nikolova Z,
Jankulovski N, Sosolceva M, Taleska G
Mojsova-Mijovska M, Marija Jovanovski-Srceva
M, Angusev D, Sazdov D, Brzanov N
Evaluation of the Effects of Elevated Intra-
abdominal Pressure on the Respiratory
Mechanics in Mechanically Ventilated Patients
Maced J Med Sci. 2013 Sep 15; 6(3):261-265
http://dx.doi.org/10.3889/MJMS.1857-5773.2013.0306.
Key words: inta-abdominal pressure; intra-
abdominal hypertension; respiratory
mechanics.

"Correspondence: Dr. Aleksandra GavrilovskaBrzanov. University Clinic of Anesthesiology, Reanimation and Intensive Care, KARIL, Faculty of Medicine, Ss Cyril and Methodius University of Skopje, Republic of Macedonia. Phone: $0038971240701 . \quad$ E-Mail gavrilovska.aleksandra@gmail.com

Received: 31-Mar-2013; Revised: 14-Jul2013; Accepted: 22-Jul-2013; Online first: 05-Sep-2013

Copyright: (c) 2013 Gavrilovska-Brzanov A. This is an open-access article distributed under the terms of the Creative Commons Attribution License, which permits unrestricted use, distribution, and reproduction in any medium, provided the original author and source are credited.

Competing Interests: The authors have declared that no competing interests exist.

\begin{abstract}
Aim: The aim of the study was to evaluate the effect of different grades of increased intraabdominal hypertension (IAH) on the respiratory mechanics.

Material and Methods: In this prospective observational clinical study, the influence of intaabdominal pressure (IAP) on respiratory parameters was assessed in 20 patients requiring mechanical ventilation with IAH grade I, 20 patients with IAH grade II, and 20 patients with grade III $\mathrm{IAH}$. Respiratory parameters were measured and recorded by a computerized system incorporated into the mechanical ventilator.

Results: A statistical difference was noticed between IAP and the dynamic respiratory parameters among the groups. Regarding the respiratory parameters positive correlation between the IAP on one hand, and peak airway pressure and resistance on the other hand was notable: IAP increased and so did pressures and the resistance in the respiratory pathways. Also the correlation between IAP, on one hand and the compliance and peripheral saturation with oxygen on the other hand, was negative. Referring the mean pulmonary pressure there wasn't correlation among IAP and mean pulmonary pressure in the groups.
\end{abstract}

Conclusion: IAP leads to impairment of the respiratory mechanics. An increase of the level of IAP is followed by an increase in the altering effects upon the respiratory system.

\section{Introduction}

By the World Society of Abdominal Compartment Syndrome intra-abdominal hypertension $(\mathrm{IAH})$ is defined as a sustained increase in intraabdominal pressure (IAP) above or equal to 12 $\mathrm{mmHg}$. IAH is graduated as shown: Grade I: IAP 12$15 \mathrm{mmHg}$, Grade II: IAP 16-20 mmHg, Grade III: IAP 21- $25 \mathrm{mmHg}$, Grade IV: IAP > $25 \mathrm{mmHg}[1,2]$. On average, more than half of the patients admitted to different intensive care unit (ICU) need mechanical ventilation (MV), which presents these patients as a high-risk group upon developing IAH [3]. IAH and MV have a big influence on the thoraco-abdominal interaction $[1,4,5]$.

Recent studies have shown that clinical judgement or physical examination is far from accurate in predicting a patients IAP. The referred standard for intermittent IAP measurement is via the urinary bladder [1, 2]. The effect of elevated IAP does not have influence only on intra-abdominal organs, it has influence either directly or indirectly on all organ systems $[6,7]$. 
Elevated IAP is one of the reasons for respiratory failure [8, 9]. IAP is transmitted to the thoracic cavity directly or indirectly thought deviation of the diaphragm. The upward movement of the diaphragm causes reduction of chest wall and lung compliance, increasing intrapleural pressure, decrease of ventilation and increase of pulmonary vascular resistance [10-13]. The main respiratory problem in IAH patients is the development of compression atelectasis of the lung parenchyma, mainly in the caudal parts near diaphragm, caused by its elevation [14]. As a result, all static and dynamic lung volumes are decreased [12, 15-17]. Adequate ventilation may only be achieved byincreased airway pressure. Further, the desired and sufficient oxygenation and ventilation is possible through MV with high positive end-expiratory pressure (PEEP), but poor compliance leads to high airway pressures [18].

The aim of the study was to assess the role of intra-abdominal pressure in the impairment of respiratory mechanics, respectively different grades of $\mathrm{IAH}$ on pulmonary compliance $(\mathrm{C})$, resistance $(\mathrm{R})$ in the lung, mean pulmonary pressure (Pmean), peak airway pressure (Ppeak), peripheral saturation with oxygen (Sat\%). We hypothesized that the level of the negative impact by the enhanced IAP on the respiratory mechanics, is correlated directly to the scale of increase of IAP. Consequently, the degree of the elevation determinates the impairment of the respiratory mechanics.

\section{Material and Methods}

This prospective longitudinal observational clinical trial was performed at the University Clinic of Anesthesiology, Reanimation and Intensive care in the Intensive Care Unit in Skopje, from June 2012 to January 2013, after obtaining an approval by our Ethics Committee.

Sixty patients were allocated into three groups ( $n=20$ each), according to a WSACS level of IAP. Group I patients with IAP of $12-15 \mathrm{mmHg}$, Group II patients with IAP $16-20 \mathrm{mmHg}$ and Group III patients with IAP 21-25 mmHg.

Adult's patients on MV with IAP above $12 \mathrm{mmHg}$ were included in the study. We excluded patients younger than 18 years, respiratory diseases, pregnancy and patients with contraindications for urinary catheterizations.

IAP was measured periodically at least every 6h. If in three consequent measurements elevated IAP more than $12 \mathrm{mmHg}$ was found, the patients were allocated in one of the groups according to the level of IAP.

Than we continued to measure IAP in $6 \mathrm{~h}$ intervals for the period of $24 \mathrm{~h}$ and the mean value of IAP from the five measurements was taken for evaluation.
According to WSACS, IAP was measured via urinary Foley catheter, an indirect, simple, minimally invasive, closed system procedure. IAP was expressed in $\mathrm{mmHg}$, measured at the end of expiration, in the supine position. The transducer was zeroed at the level of the mid-axillary line, with an instillation volume of no greater than $25 \mathrm{ml}$ of saline, and measured 30-60 seconds to allow bladder detrusor muscle relaxation. IAP measuring was stopped earlier, if IAP stabilized within a normal range of $12 \mathrm{mmHg}$ and lower. Measuring technique is demonstrated in Figure 1.

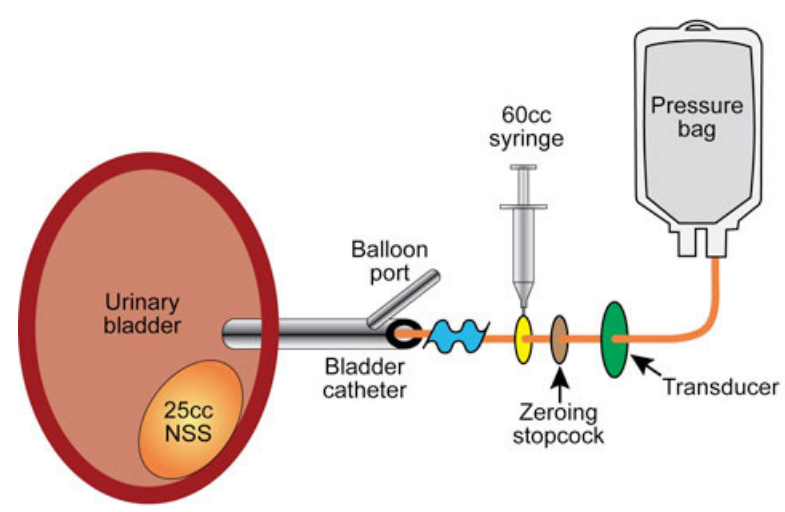

Figure 1: Intravesicular manometry device. Intravesical pressure monitoring involves measuring bladder pressure after infusing 25 $m L$ of $0.9 \%$ normal saline.

In all patients admitted in ICU, according to standard sterile procedure urinary Foley catheter was placed. Intubated or tracheostomated patients were continuously sedated in accordance to the Richmond Agitation Sedation scale with Midazolam 5-15 mg/h and Fentanyl 0.5-2.5 mg/h. Paralyzing agents were not used. If patients were submitted under vazoactive drugs rate of infusion was stabile during whole procedure. A critical care ventilator Evita 4 (Dräger medical, Lübeck, Germany) was set by the attending physician in the volume-control mode with tidal volume (VT) $8 \mathrm{ml} / \mathrm{kg} / \mathrm{bw}$ with fraction of inspired oxygen $\left(\mathrm{FiO}_{2} \%\right)<40 \%$, an inspiration: expiration ratio I: E/1:2. The Respiratory rate (RR) was adjusted to maintain an end tidal $\mathrm{CO}_{2}$ of 35 to $45 \mathrm{mmHg}$, positive end-expiratory pressure (PEEP) $5 \mathrm{cmH}_{2} \mathrm{O}$. During the time of measuring IAP the main respiratory variables were recorded from the computer incorporated in the mechanical ventilator. The variables provided by the computer were pulmonary dynamic compliance (Cdyn), resistance (Rdyn) in the lung, mean pulmonary pressure (Pmean), and peak airway pressure (Ppeak). Further the peripheral saturation with oxygen (Sat\%) was recorded by pulse oximetry. Respiratory variables were assessed $20 \mathrm{~min}$ after tracheal aspiration in well sedated patients.

The data were analyzed using Difference test, Analysis of Variances and Tukey Post Hock HSD test. A $p<0.05$ was considered statistically significant. 


\section{Results}

The demographic data of the patients were similar in all three groups, with respect to sex, age, weight, height and BMI (Table 1). There was variety of diagnosis the mostly represented clinical diagnosis at the I and III group was acute abdomen with $25 \%$ in the group I and 30\% in the Group III, in the group II there was lleus occupying $25 \%$.

As a value of IAP we used the mean value from all five measurements. The results we obtained for IAP are summarized in Table 1.

Table 1: Patients characteristic.

\begin{tabular}{ccccc}
\hline $\begin{array}{c}\text { Patients } \\
\text { characteristics }\end{array}$ & Group I & Group II & Group III & P value \\
\hline Sex M/F & $11 / 9$ & $10 / 10$ & $16 / 4$ & $\mathrm{NS}$ \\
Age/year & $53 \pm 17$ & $54 \pm 12$ & $56 \pm 12$ & $\mathrm{NS}$ \\
BMI, kg/m & $26 \pm 4$ & $28 \pm 2$ & $27 \pm 4$ & $\mathrm{NS}$ \\
Height, cm & $172 \pm 9$ & $167 \pm 9$ & $169 \pm 10$ & $\mathrm{NS}$ \\
Weigh, $\mathrm{kg}$ & $78 \pm 5$ & $69 \pm 7$ & $77 \pm 6$ & $\mathrm{NS}$ \\
IAP, $\mathrm{mmHg}$ & $13 \pm 1$ & $18 \pm 1$ & $22 \pm 1$ & $\mathrm{P}<0,001$ \\
\hline
\end{tabular}

$\mathrm{BM} \mathrm{I}=$ body $\max$ index; $\mathrm{F}=$ female; $\mathrm{IAP}=$ intra=abdominal pressure; $\mathrm{NS}=$ not significant Data are presented as mean \pm standard deviation.

$\mathrm{ETCO}_{2}$ recorded in the groups were $39 \pm 3$ group I, $40 \pm 2$ group II and $39 \pm 4$ in group III. There wasn't significant changes between the set and measured tidal volume $\mathrm{Vt}=8 \pm 0.4 \mathrm{ml} / \mathrm{kg} / \mathrm{bw}$ with constant level of PEEP $5 \mathrm{cmH}_{2} \mathrm{O}$. Sat\% in the patients groups were: in group I: 99\%,in group II Sat\% was lower with $98 \%$ group III had lowest values of Sat\% $96 \%$.There was statistically significant difference in Sat\% in the groups and between them $(p<0.05)$. Related to IAP there was negative correlation with the Sat $\%$ in all three groups $(r=-0.3456$ for $p<0.001 ; r=-$ 0.1968 for $p=0.050$; $r=-0.3365$ for $p=0.001$ ).

$\mathrm{IAH}$ in all three groups significantly changed compliance at every level of elevated IAP. Compared to group I the compliance was reduced by $30 \%$ in group II and by $60 \%$ in group III (Table 2).

There was statistically significant negative correlation between IAP and the compliance in group II $(r=-0.4060$ for $p<0.001)$ and Group III $(r=-0.4827$ for $\mathrm{p}<0.001)$.

Resistance increased significantly with rising IAP. Compared to group I the resistance was 33\% higher in group II and 90\% higher in group III.There was statistically significant differences in resistance between the three groups, $(p<0.001)$. During calculation, we noticed statistically significant positive correlation between IAP and resistance in the group II $(r=0.3812$ for $p<0.001)$ and group III $(r=0.4826$ forp<0.001).

Refer to mean pulmonary pressure, there was statistically difference in the groups $(p<0.001)$ and among the groups $(p<0.001)$ but without correlation between IAP and mean pulmonary pressure, except in group I $(r=0.2147$ for $p=0.032)$.
As concerns Turkey HSD test if differences of average value are investigating particularly there are statistically significances among the groups for $p<0.05$.

Table 2: Respiratory mechanics in the Groups

\begin{tabular}{|c|c|c|c|c|}
\hline $\bar{N}$ & Group I & Group II & Group III & One way - ANOVA \\
\hline Sat $\%$ & $99 \pm 1$ & $98 \pm 1$ & $96 \pm 1$ & $\begin{array}{l}F=320,19 \\
P<0,001\end{array}$ \\
\hline $\begin{array}{l}\text { Peak P } \\
\mathrm{cmH}_{2} \mathrm{O}\end{array}$ & $18 \pm 2$ & $25 \pm 2$ & $30 \pm 2$ & $\begin{array}{c}F=765,94 \\
P<0,001\end{array}$ \\
\hline $\begin{array}{l}\text { Pmean } \\
\mathrm{cmH}_{2} \mathrm{O}\end{array}$ & $9 \pm 2$ & $12 \pm 2$ & $16 \pm 3$ & $\begin{array}{l}F=245,97 \\
P<0,001\end{array}$ \\
\hline $\begin{array}{c}\mathrm{Cdyn} \\
\mathrm{m} / / \mathrm{cmH}_{2} \mathrm{O}\end{array}$ & $59 \pm 10$ & $41 \pm 6$ & $25 \pm 3$ & $\begin{array}{c}F=551,84 \\
P<0,001\end{array}$ \\
\hline $\begin{array}{c}\mathrm{Rdyn} \\
\mathrm{cm} \mathrm{H}_{2} \mathrm{O} / \mathrm{L} / \mathrm{sec}\end{array}$ & $9 \pm 2$ & $13 \pm 2$ & $18 \pm 2$ & $\begin{array}{l}F=801,94 \\
P<0,001\end{array}$ \\
\hline
\end{tabular}

Cdyn = dynamic compliance; $F=$ ratio of the variance calculated among the means to the variance within the samples; Ppeak $=$ peak pulmonary pressure; Pmean $=$ mean pulmonary pressure; Rdyn = dynamic resistance. Data are presented as mean \pm standard deviation.

We revealedpositive correlation for peak airway pressure and. IAP in group II $(r=0.4844$ for $p<0.001)$ and group III $(r=0.3950$ for $p<0.001)$ (Table.2). Group III was with highest peak airway pressure compared with group I for $77 \%$ and group II with 33\% higher than group I.

\section{Discussion}

Our main findings were that monitoring of IAP in the ICU is indispensable due to impairment of mechanical properties of the respiratory system, caused by abdomino-thoracic pressure transmission. Consequently, high airway pressures are needed during MV.

There are many studies examining the interaction between abdominal and thoracic compartment in humans and animals, in healthy and diseased lung [9, 16, 19-21].

The present paper differs from the previous ones in the following issues: patients were prospectively stratified a priori according to their levels of elevated IAP despise the underlying pathology. We decided to use the threshold level of $12 \mathrm{mmHg}$ to identify patients with $\mathrm{IAH}$, compared with patients with normal IAP, as suggested by the Guidelines of WSACS [1, 2]. Respiratory mechanics were simultaneously measured at comparable ventilator settings and at standard level of PEEP.

We used the following parameters for evaluating the respiratory mechanics: pressure in the lungs, compliance and resistance in the respiratory system as most often used in clinical practice [17].

Evaluation of these parameters nowadays is facilitated, thanks to the technological improvement (computers incorporated in critical care ventilators), which allow their continuous and noninvasive evaluation.

Our findings also indicate there was effect of IAP on pulmonary mechanics, as it's previously 
revealed in healthy animals [9]. Increased IAP markedly affects the mechanical properties of the respiratory system, lung and chest wall, and the respiratory function in different experimental settings. Thus, this indicates a positive correlation between the chest wall elastance and the IAP levels [9].

Peak airway pressure and Pmean pulmonary pressure increased with rising of IAP. In group I, mild increased IAP does not mainly affect pulmonary mechanics. However, as IAP increases, in group II and III so does the Peak airway pressure. Refer to mean pulmonary pressure there was a significant difference in mean pulmonary pressure between groups but without significant correlation between IAP and mean pulmonary pressure.

Following experimental clinical trial shows results which are correspondent with ours, regarding to IAP, Peak and Pmean airway pressure [9, 20-22].

Regli et al. examined the effect of PEEP on the FRC, due to unclear optimal ventilation strategy for patient with $\mathrm{IAH}$. They discovered significant increasing in Peak airway pressure and decreasing of compliance in thirteen anesthetized pigs during elevation of IAP from $12 \mathrm{mmHg}, 18 \mathrm{mmHg}$ and 28 $\mathrm{mmHg}$, while mean pulmonarypressure didn't show any changes. Pigs where mechanically ventilated, with settings of the ventilator same to our study. They imply that PEEP level inferior to the corresponding IAP cannot prevent FRC decline in the setting of IAH [21].

Observation of $\mathrm{IAH}$ in diseased lung is performed by Krebs at al.. In their study, they found that ALI/ARDS patients with $\mathrm{IAH}$, as compared to those with normal IAP, were characterized by no differences in gas-exchange, respiratory mechanics, partitioned into its lung and chest wall components, as well as hemodynamics. Also, there is decreased elastance of the respiratory system and the lung, but no differences in alveolar recruitment and oxygenation or hemodynamics, when PEEP was increased at 10 and $15 \mathrm{cmH}_{2} \mathrm{O}$ [23].

Patients with moderate increased IAP from group I are with normal values for the compliance but as IAP increases the compliance in group II is consequently decreasing and is lowest in group III. The study previously mentioned, by Quintel at al. indicated that decreased chest wall compliance results in decreased respiratory system compliance, the lung compliance being nearly unaffected, except in the case of concomitant ARDS [9]. Differentiating between changes in lung and chest wall compliance during elevated IAP requires assessment of pleural pressure [24].

One experiment that is more significant is on the pigs from Mutoh et al. They hypothesized that IAH will initially decrees the compliance of the thoracic cavity, but with decreasing of the VT they will decrees the lung compliance also, what makes the total compliance of the respiratory system decreased. They obtain $39 \%, 48 \%, 47 \%$ successive decreasing in the compliance of the lung, thoracic cavity and total compliance of the respiratory system [20]. The present study showed that the dynamic compliance of the lung is decreasing, regarding to elevation of the IAP, during ventilation with constant VT.

The resistance in our study is significantly enhanced with elevation of IAP. There is 90\% increscent in resistance between group I and III, which mean that we need much higher pressure for ventilating the lungs. In the experiment of Quintel findings are matching with ours, correlating the influences of elevated IAP on resistance.

They revealed that depending on the $\mathrm{VT}$, resistance in the respiratory system is always increasing along with increasing of IAP [9]. Compared with their study, in ours we used fixed VT and constant PEEP, and investigated higher level of IAP > $20 \mathrm{mmHg}$.

Valuating the deleterious effects of increased IAP, Sakra et al. analyses forty five patients who underwent on laparoscopic surgery, anesthetized, on MV with settings as the same as in our study twenty minutes after insufflations of $\mathrm{CO}_{2}$ they monitored the variables. Peak airway pressure was significantly increased and the compliance decreased, without significant changes in mean pulmonary pressure [22] confirming our standings on patients in ICU with elevated IAP from a different pathology.

Malbrain et al. showed correlation between IAP and peak airway pressure and indicated inverse correlation between IAP and compliance, in their study analyzing the pressure /volume curves in five mechanically ventilated patients [25].

With review of the available publications and literature, Wauters et al. concluded that IAP seriously affects the respiratory mechanics: increasing the resistance, decreasing the compliance with consequents demands of bigger pressures for ventilating the lungs. This makes an impact, causing increase of the peak airway pressure [24].

Conclusion: In our study, we show that monitoring of IAP in ICU is indispensable. Increased IAP remarkably affects respiratory function in such a way that it has an impact on daily clinical practice. IAH results with an impairment of respiratory mechanics. A statistical difference $(p<0.05)$ was noticed between IAP and the respiratory parameters within the groups.. IAP has negative reliance on the compliance. With increasing of IAP, compliance is decreasing, but this not make references to Group I, IAP of $12-15 \mathrm{mmHg}$. The same is with the influence on the Sat\%: As the IAP increases, the Sat\% decrease. Concerning to peak airway pressure and resistance they have positive correlation with IAP. As the IAP increases, so does the maximal pressure and the resistance within the respiratory pathways. Exception is only the group I 
in which increased IAP of 12-15 $\mathrm{mmHg}$ does not have correlation with resistance. These results may also have importance for the optimal ventilatory management of critically ill patients with IAH within respect to minimize ventilator induced lung injury.

This paper shows that the elevation of the IAP is followed by an increase in the altering effects upon the respiratory system, more than that, the degree of the enhance of the IAP, conducts and correlate with the degree of enhance of the respiratory malfunction.

Limitations of present study were one center study, small group of patients with different pathology. We measured Ppeak inspiratory pressure not plateau pressure that is more reflective of alveolar pressure. Patients with short stay in ICU lass than $24 \mathrm{~h}$ we excluded.

\section{References}

1. Malbrain ML, Cheatham ML, Kirkpatrick A, et al. Results from the International Conference of Experts on Intra-abdominal Hypertension and Abdominal Compartment Syndrome. I. Definitions. Intensive Care Med. 2006;32:1722-32.

2. World Society of the Abdominal Compartment Syndrome http://www.wsacs.org/ Assessed October 12.02.2013.

3. Metnitz PG, Metnitz B, Moreno RP, at al. Epidemiology of mechanical ventilation: analysis of the SAPS 3 database. Intensice Care Med. 2009; 35:816-25.

4. Malbrain ML, Chiumello D, Pelosi $P$, et al. Incidence and prognosis of intraabdominal hypertension in a mixed population of critically ill patients: A multiple-center epidemiological study. Crit Care Med. 2005;33:315-22.

5. Malbrain ML, Chiumello D, Pelosi P, Wilmer A, Brienza N, Malcangi $\mathrm{V}$, et al. Prevalence of intra-abdominal hypertension in critically ill patients: a multicentre epidemiological study. Intensive Care Med. 2004; 30:822-829.

6. Cheatham ML, Malbrain ML, Kirkpatrick A, et all. Results from the International Conference of Experts on Intra-abdominal Hypertension and Abdominal Compartment syndrome. II. Recommendations. Intensive Care Med. 2007; 33(6):p. 95162.

7. Cheatham ML. Abdominal Compartment Syndrome. Pathophysiology and Definitions. Scandinavian Journal of Trauma Resuscitation and Emergency Medicine. 2009; 17-10.

8. Malbrain ML, Deeren D, De Potter TJ. Intra-abdominal hypertension in the critically ill: it is time to pay attention. Curr Opin Crit Care. 2005;11:156-71.

9. Quintel M, Pelosi P, Caironi P, et all. An increase of abdominal pressure increases pulmonary edema in oleic acid-induced lung injury. Am J Respir Crit Care Med. 2004; 169:534-541.

10. Hunter JD, Damasi Z. Intraabdominal hypertension and the abdominal compartment syndrome. Anaesthesia. 2004; 59:899.

11. Sieh KM, Chu KM, Wong J. Inrtaabdominal hypertension and the abdominal compartment syndrome. Langenbeck's Arch Surg. 2001; 386:53.

12. Moore FK, Hargest R, Martin M, Delicata RJ. Intraabdominal hypertension and the abdominal compartment syndrome. Br. J. Surg. 2004; 91:1102.

13. Fahy BG,Barnas GM, Flowers JL, et al. The effects of increased abdominal pressure on lung and chest wall mechanics during laparoscopic surgery. Anesthe Analg. 1995; $81: 744-50$
14. Strang CM, Freden F, Maripuu E, Hachenberg $T$ and $G$. Hedenstierna. Ventilation-perfusion distributions and gas exchange during carbon dioxide-pneumoperitoneum in a porcine model. British Journal of Anaesthesia. 2010;105(5): 691-7.

15. Sugrue M. Abdominal compartment syndrome. Curr Opin Crit Care. 2004; 10:132.

16. Obeid, F, Saba A, Fath J, et al. Increases in intra-abdominal pressure affect pulmonary compliance. Arch Surg. 1995; 130:544.

17. Stenqvist $\mathrm{O}$. Practical assesement of respiratory mechanics. $\mathrm{Br}$ J Anaesth. 2003; 91:92-105.

18. De Keulenaer BL, De Backer A, Schepens DR, Daelemans R, Wilmer A, Malbrain ML. Abdominal compartment syndrome related to noninvasive ventilation. Intensive Care Med. 2003; 29:1177.

19. Gattinoni L, Pelosi P, Suter PM, Pedoto A, Vercesi P, Lissoni A. Acute respiratory distress syndrome caused by pulmonary and extrapulmonary disease. Different syndromes?. Am J Respir Crit Care Med. 1998;158:3-11.

20. Mutoh T, Lamm WJ, Embree LJ, Hildebrandt J, Albert RK. Abdominal distension alters regional pleural pressures and chest wall mechanics in pigs in vivo. J Appl Physiol. 1991;70:2611-2618.

21. Regli A, Hockings LE, Musk GC, et al. Commonly applied positive end-expiratory pressure do not prevent functional residual capacity decline in the setting of intra-abdominal hypertension: a pig model. Critical Care. 2010; 14:R128.

22. Skarpa N, Matala ME, Makris A, Sarridou D, Spanomanoli A, Sgouromalli - Kostaki S. Effects of pneumoperitoneum on pulmonary mechanics during laparoscopic cholecystectomy. 2011; $28: .70$.

23. Krebs $\mathrm{J}$, Pelosi $\mathrm{P}$, Tsagogiorgas $\mathrm{C}$, Alb $\mathrm{M}$ and Luecke $\mathrm{T}$. Effects of positive end-expiratory pressure on respiratory function and hemodynamics in patients with acute respiratory failure with and without intra-abdominal hypertension: a pilot study. Critical Care. 2009; 13:R160.

24. Wauters J, Wilmer A, Valenza F. Abdomino-thoracic transmission during ACS: facts and figures. Acta Clin Belg Suppl. 2007;(1):200-5.

25. Malbrain $M L$, Deeren $D H$, De Potter $T$, Libeer $C$, Dits $H$. Partitioning of respiratory mechanics in intra abdominal hypertension (IAH). Sheraton Noosa Resort, Queensland, Australia, December 2004: 6-8. 